\title{
Synthesis of ZnO nanoparticles by a hybrid electrochemical-thermal method: influence of calcination temperature
}

\author{
F. Hassan ${ }^{1}$, M. S. Miran $^{1}$, H. A. Simol ${ }^{1,2}$, M. A. B. H. Susan $^{1}$ and M. Y. A. Mollah ${ }^{1 *}$ \\ ${ }^{1}$ Department of Chemistry, University of Dhaka, Dhaka 1000, Bangladesh \\ ${ }^{2}$ Centre for Advanced Research in Sciences, University of Dhaka, Dhaka 1000, Bangladesh
}

\begin{abstract}
$\mathrm{ZnO}$ nanoparticles (NPs) with size less than $100 \mathrm{~nm}$ were successfully prepared by a hybrid electrochemical-thermal method using metallic zinc and $\mathrm{NaHCO}_{3}$ without the use of any zinc salt, template or surfactant. The NPs were characterized by Fourier transform infra-red (FT-IR) spectroscopy, UV-visible spectroscopy, photoluminescence spectroscopy (PL), thermo-gravimetric analysis (TGA), X-ray diffraction (XRD), scanning electron microscopy (SEM) and energy dispersive X-ray (EDX) spectroscopy. UV-visible spectral analysis indicated that the particle size increased with increasing calcination temperature. The band gap (3.91-3.83 eV) was higher for synthesized ZnO NPs than their bulk counterparts $(3.37 \mathrm{eV})$. The FT-IR spectra at different calcination temperatures showed the characteristic band for $\mathrm{ZnO}$ at $450 \mathrm{~cm}^{-1}$ to be prominent with increasing temperature due to the conversion of precursor into $\mathrm{ZnO}$. The wurtzite hexagonal phase was confirmed by $\mathrm{XRD}$ analyses for $\mathrm{ZnO}$ NPs calcined at $700{ }^{\circ} \mathrm{C}$. The green photoluminescent emission from $\mathrm{ZnO}$ NPs at different calcination temperatures is considered to be originated from the oxygen vacancy or interstitial related defects in ZnO. SEM images clearly showed that the NPs are granular and of almost uniform size when calcined at higher temperatures. EDX spectra further confirmed the elemental composition and purity of $\mathrm{ZnO}$ obtained on calcination at $700{ }^{\circ} \mathrm{C}$. The NPs are well dispersed near or above calcination temperature of $700{ }^{\circ} \mathrm{C}$.
\end{abstract}

Keywords: $\mathrm{ZnO}$ nanoparticles; Semiconductor; Calcination; Particle size; Hybrid-electrochemical-thermal method

\section{Introduction}

Zinc oxide $(\mathrm{ZnO})$, due to its excellent semiconducting and gas sensing properties and photocatalytic and antibacterial activities, is an important material for photovoltaic cells (Rensmo et al.., 1997; Bauer et al., 2001; Thool et al.., 2014), optoelectronic devices (Tennakone et al., 1999; Zhang et al., 2002; Govender et al., 2002) and sensors (Dong et al., 1997; Gupta, 1990; Henning et al., 1990; Chaturvedi et al., 2012). The recent bias has been shifted towards the investigation of $\mathrm{ZnO}$ at nano-scale. Development of a suitable low-cost method operable at ambient temperature for the preparation of $\mathrm{ZnO}$ nanoparticles with enhanced semiconducting properties along with other properties remains a challenge to the researchers. The growth kinetics of $\mathrm{ZnO}$ nanoparticles (NPs) from a basic solution of zinc acetate using different solvents has been investigated to demonstrate that the particle growth and coarsening are strongly dependent on the solvent (Syeeda et al., 2008). Propanol-2 has been found to be the most suitable solvent. The effect of surfactants on the growth kinetics of $\mathrm{ZnO}$ NPs in reverse micellar system has also been reported (Ahmed et al., 2013). Moreover, $\mathrm{ZnO} @ \mathrm{Ag}$ core@shell NPs have been prepared by using water-in-oil microemulsions (Satter et al. 2014). Particle size determination by effective mass model (EMM) (Holleman et al., 2001; Brus 1986) indicates a uniform particle size distribution of $\mathrm{ZnO}$ NPs in reverse micellar solutions; and both anionic, viz. sodium dodecyl sulfate (SDS) and cationic, cetyltrimethylammonium bromide (CTAB) surfactants effectively influences the growth kinetics of $\mathrm{ZnO}$ NPs.

Although reverse micellar systems have proved themselves as promising media for preparation of $\mathrm{ZnO} \mathrm{NPs}$, isolation of $\mathrm{ZnO}$ NPs in the solid state is troublesome and more often limited by coagulation. For large scale preparation of $\mathrm{ZnO}$ NPs, the ease of preparation and extraction in the solid state are very important and a novel methodology to prepare $\mathrm{ZnO}$ NPs with controllable size, desirable morphology and homogeneous and uniform distribution of particles is critically sought for. In this context, electrochemical methods have gained considerable interest because of their simplicities, low temperature operations, and viabilities for commercial production (Chandrappa et al., 2010; Zhu et al., 2006; Geeetha and Thilagavathi, 2010). The effects of electrolyte concentration and current density on the yield for $\mathrm{ZnO}$ NPs have already been reported and the effect of

\footnotetext{
*Corresponding author: E-mail: myamollah@hotmail.com
} 
calcination temperatures on the morphology and size of $\mathrm{ZnO}$ has been touched upon (Chandrappa et al., 2010); but a clear understanding of the effect of calcination temperature on the morphology and size of $\mathrm{ZnO}$ still remains an unresolved issue. A systematic approach to thoroughly investigate the growth kinetics of $\mathrm{ZnO}$ NPs at different calcination temperatures and tune size and morphology for task-specific applications is yet to be made.

In this study, we report the synthesis of ZnO NPs by an electrochemical-thermal method using metallic zinc as a precursor avoiding the use of any surfactants or template. Particular emphasis has been given on the influence of calcination temperature on the morphology and size of $\mathrm{ZnO}$ NPs. The ultimate goal has been to optimize the condition for large scale production of $\mathrm{ZnO}$ with controllable size and morphology using the low-cost hybrid method.

\section{Materials and methods}

\section{Materials}

High purity zinc metal plates (99.99\%) were purchased from Sisco Research Laboratories and were cut into pieces of required size and shape for use as electrodes. Sodium bicarbonate (Merck, Germany) and nitric acid (Merck, Germany) were used without any further purification. Ultrapure water (resistivity, $r=18.0 \mathrm{M} \Omega \mathrm{cm}$ ) used in this study was collected from a water purifier (BOECO pure, model- BOE 8082060, Germany).

\section{Preparation of $\mathrm{ZnO} N P S$}

A two-electrode monopolar electrolytic cell (Chandrappa et $a l$. , 2010) with zinc as sacrificial anode was used for electrochemical synthesis of $\mathrm{ZnO}$. The electrodes were supported on a holder made of ebonite and placed inside the electrolyte solution comprising $0.009 \mathrm{M} \quad \mathrm{NaHCO}_{3}$. Electrolysis was carried out on average temperature of ca. 30 ${ }^{\circ} \mathrm{C}$ for $1 \mathrm{~h}$ by passing fixed amount of current of $2 \mathrm{~A}$, following the condition optimized in the literature (Chandrappa et al., 2010). The resulting white precipitates were filtered and air-dried for 12 hours. These were used as precursors and calcined at different temperatures from as low as $60{ }^{\circ} \mathrm{C}$ to maximum of $700{ }^{\circ} \mathrm{C}$ for 1 hour. The possible chemical reaction scheme is-

$$
\begin{aligned}
& \mathrm{NaHCO}_{3}(\mathrm{~s})+\mathrm{H}_{2} \mathrm{O}(\mathrm{l}) \leftrightarrow \mathrm{Na}^{+}(\mathrm{aq})+\mathrm{HCO}_{3}^{-}(\mathrm{aq}) \\
& \mathrm{HCO}_{3}^{-}(\mathrm{aq})_{+} \mathrm{H}_{2} \mathrm{O}(\mathrm{l}) \leftrightarrow \mathrm{H}_{2} \mathrm{CO}_{3}(\mathrm{aq})+\mathrm{OH}^{-}(\mathrm{aq}) \\
& \mathrm{Zn}(\mathrm{s}) \rightarrow \mathrm{Zn}^{2+}(\mathrm{aq})+2 \mathrm{e}^{-} \\
& \mathrm{Zn}^{2+}(\mathrm{aq})+2 \mathrm{OH}^{-}(\mathrm{aq}) \rightarrow \mathrm{Zn}(\mathrm{OH})_{2}(\mathrm{~s}) \downarrow \\
& \mathrm{Zn}^{2+}(\mathrm{aq})+2 \mathrm{HCO}_{3}^{-}(\mathrm{aq}) \rightarrow \mathrm{ZnCO}_{3}(\mathrm{~s}) \downarrow+\mathrm{H}_{2} \mathrm{O}(\mathrm{l})+\mathrm{CO}_{2}(\mathrm{~g})
\end{aligned}
$$

Upon calcination precursors $\left(\mathrm{Zn}(\mathrm{OH})_{2}\right.$ and $\left.\mathrm{ZnCO}_{3}\right)$ were converted to $\mathrm{ZnO}$.

\section{Characterization of $\mathrm{ZnO} N P S$}

$\mathrm{ZnO}$ NPs were characterized to understand the changes of physical and optical properties with calcination temperature. The band gap of the ZnO NPs was calculated from UV-visible (UV-vis) spectrum (Shimadzu 1650) by using EMM (Holleman et al., 2001; Brus, 1986). An FT-IR spectrometer (Shimadzu FT-IR IR-Prestige-21) was used to identify products at different temperatures. Thermogravimetric analysis (TG-DTA 7200, Hitachi, Japan) of the precursor was performed to find out temperature for its conversion to $\mathrm{ZnO}$ and to predict the possible chemical changes taking place during calcination. Thermal analysis of about $10 \mathrm{mg}$ of the sample was carried out at a heating rate of $5{ }^{\circ} \mathrm{C}$ per min from ambient temperature upto $900{ }^{\circ} \mathrm{C}$ in an alumina pan under nitrogen atmosphere. Photoluminescence (PL) spectroscopy (F-7000 FL Spectrophotometer) was used to study the surface defect. An X-ray diffractometer (PAN analytical X' Pert PRO XRD PW 3040; $\mathrm{Cu} K$ radiation) was used to analyze the phase composition. Scanning electron microscopy (SEM) was used for morphological analysis. The stoichiometry of the calcined samples was examined by the energy dispersive X-ray (EDX) spectroscopy. The SEM images and EDX spectra of prepared samples were recorded using a SEM and EDX spectrometer (Hitachi S-3400N, Japan).

\section{Results and discussion}

\section{FT-IR spectroscopy}

FT-IR spectra of precursor and ZnO NPs calcined at different temperatures (Fig.1) were recorded in the range of $319-4000 \mathrm{~cm}^{-1}$.

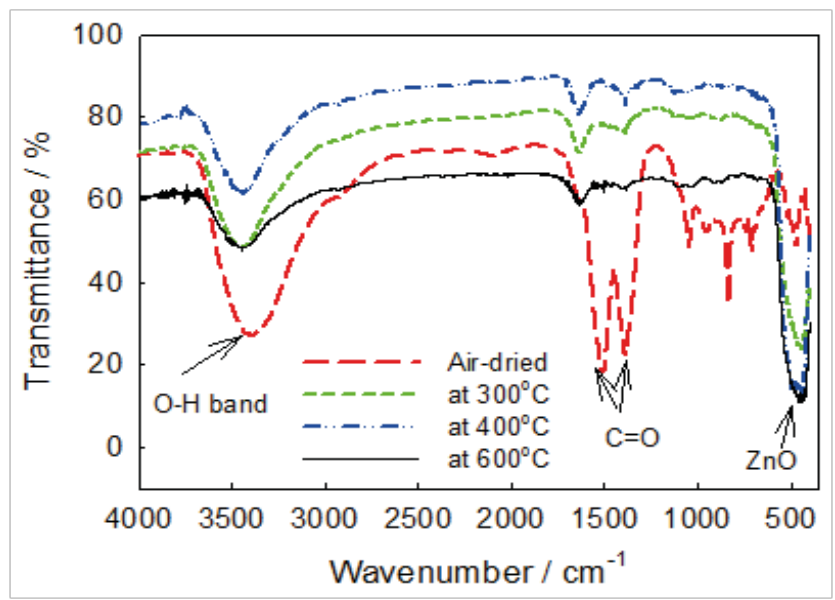

Fig. 1. FT-IR spectra of the precursor and ZnO NPs calcined at different temperatures. 
The band at $450 \mathrm{~cm}^{-1}$ is characteristic of $\mathrm{ZnO}$ (Lili et al., 2006). The absorption bands of air dried sample correspond to $\mathrm{ZnCO}_{3}$ and $\mathrm{Zn}(\mathrm{OH})_{2}$. On heating to $300{ }^{\circ} \mathrm{C}$ and higher temperatures, the band at 1500, 1387 and $700-1100 \mathrm{~cm}^{-1}$ disappear and a band at $450 \mathrm{~cm}^{-1}$ for $\mathrm{Zn}=\mathrm{O}$ appears. Absorbed water is present in all samples. The stretching modes of vibrations in asymmetric and symmetric $\mathrm{C}=\mathrm{O}$ vibration bands and bending vibrations of $\mathrm{Zn}(\mathrm{OH})_{2}$ are observed at 1387 and $1500 \mathrm{~cm}^{-1}$. The lattice vibration bands of $\mathrm{CO}_{3}{ }^{2-}$ appear within $700-1100 \mathrm{~cm}^{-1}$ due to the lattice vibration of $\mathrm{CO}_{3}^{2-}$ in air dried sample, but is absent in calcined samples (Yongning et al., 1996). Moreover, the band in the range $3200-3600 \mathrm{~cm}^{-1}$ is due to intermolecular hydrogen bond due to absorbed water.

\section{Thermogravimetric analysis (TGA)}

Fig. 2 shows the TG-DTA patterns for air dried $\mathrm{ZnO}$ precursor. The first weight loss in the range of $30-100{ }^{\circ} \mathrm{C}$ is due to removal of surface adsorbed water. About $2.41 \%$ weight loss within $100-150{ }^{\circ} \mathrm{C}$ correspond to the removal of trapped water molecule and desorption of hydroxide ion (Chandrappa et al., 2010). The major weight loss of $17.87 \%$ is observed within $150-280{ }^{\circ} \mathrm{C}$ for decompositions of $\mathrm{Zn}(\mathrm{OH})_{2}$ and $\mathrm{ZnCO}_{3}($ Chandrappa et al., 2010). The precursor loses its weight (1.86\%) in the temperature range of 300-440 ${ }^{\circ} \mathrm{C}$, possibly due to the decarbonation process at higher temperature (Vágvölgyi et al., 2008). Although decarbonation is expected to be completed within $280{ }^{\circ} \mathrm{C}$, slower diffusion of $\mathrm{CO}_{2}$ from the core of particles is slow to exhibit weight loss in this temperature range. Some oxygen loss may occur at higher temperature (Vágvölgyi et al., 2008 ), which is observed between $440-650^{\circ} \mathrm{C}$ (weight loss $0.4 \%)$.

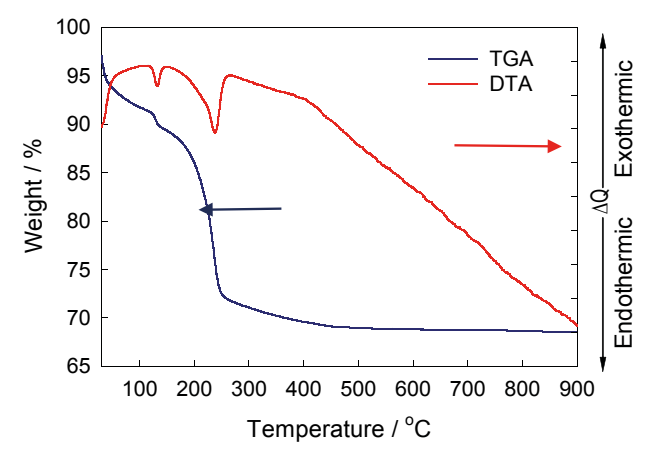

Fig. 2. TG-DTA pattern of $\mathrm{ZnO}$ precursor.

There are two endothermic peaks in the DTA curve; one $\left(120-145^{\circ} \mathrm{C}\right)$ corresponds to the evaporation of absorbed and trapped water and another $\left(150-262{ }^{\circ} \mathrm{C}\right)$ corresponds to the simultaneous decomposition of hydroxide and carbonate (Chandrappa et al., 2010). It is concluded that the formation of $\mathrm{ZnO}$ takes place on heating to $300{ }^{\circ} \mathrm{C}$; but complete crystallinity is achieved on heating at $700{ }^{\circ} \mathrm{C}$.

\section{UV-Visible spectroscopy}

The UV-visible absorption spectra of different samples dispersed in water are shown in Fig. 3. The cut-off wavelength was obtained from the absorption spectra following the procedure described in literature (Hale et al., 2005). The slope at half the peak maximum was estimated and the cut-off wavelength was measured from where the tangent crossed the $\lambda$ - axis (X-intercept).

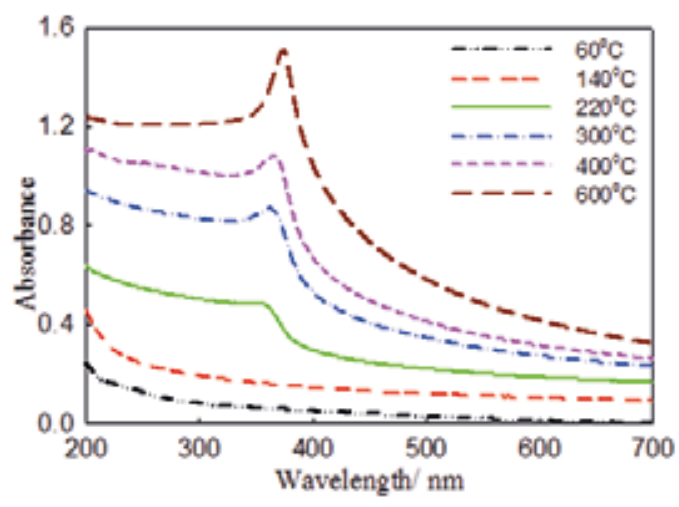

Fig. 3. UV-vis spectra of ZnO NPs calcined at different temperatures.

Table I. Band gap energy of ZnO NPs at different calcination temperatures (from Fig. 3).

\begin{tabular}{ccc}
\hline $\begin{array}{c}\text { Calcination } \\
\text { temperature }\left({ }^{\circ} \mathrm{C}\right)\end{array}$ & $\begin{array}{c}\text { Cut-off wavelength } \\
(\mathrm{nm})\end{array}$ & $\begin{array}{c}\text { Band gap energy } \\
(\mathrm{eV})\end{array}$ \\
\hline 60 & ---- & --- \\
140 & --- & ---- \\
220 & 407 & 3.89 \\
300 & 406 & 3.88 \\
400 & 406 & 3.87 \\
600 & 407 & 3.86 \\
\hline
\end{tabular}

Fig. 3 shows that the corresponding absorption band $\left(\lambda_{\max }\right)$ remained almost identical (406-407 $\mathrm{nm}$ ) with change in calcination temperature from 220 to $600{ }^{\circ} \mathrm{C}$. The band gap energy was found in the range of 3.86-3.89 eV and did not show any noticeable change with growth of the NPs on increasing calcination temperature. Particle size estimated from EMM shows the values in the range of 1.52 to $1.55 \mathrm{~nm}$. 
Formation of NPs could not be marked between 60 to $140{ }^{\circ} \mathrm{C}$. The $\mathrm{ZnO}$ NPs generated via electrochemical method are in blue region compared to the bulk $\mathrm{ZnO}(3.37 \mathrm{eV})$ in agreement with the literature data (Chandrappa et al., 2010; Wang et al. 2009). The difference in the band gap is related to the presence of vacancies and dopants (Wang et al. 2009).

\section{Photoluminescence emission}

Photoluminescence spectra of $\mathrm{ZnO}$ NPs at different calcination temperatures are given in Fig. 4. These typically consist of a weak UV emission band (a) and a sharp visible emission band (b) in agreement with literature (Singh et al., 2008). The UV emission band related to a near band-edge transition of $\mathrm{ZnO}$ appears at ca. $337 \mathrm{~nm}$. A significant enhancement (ca. 300 times) is observed for the intensity of air-dried sample that partially covers violet-blue region in the visible spectrum. Thus, it is assumed that the blue emission of air-dried sample (Fig. 4 (a) originates from transitions involving zinc interstitial defect structures.

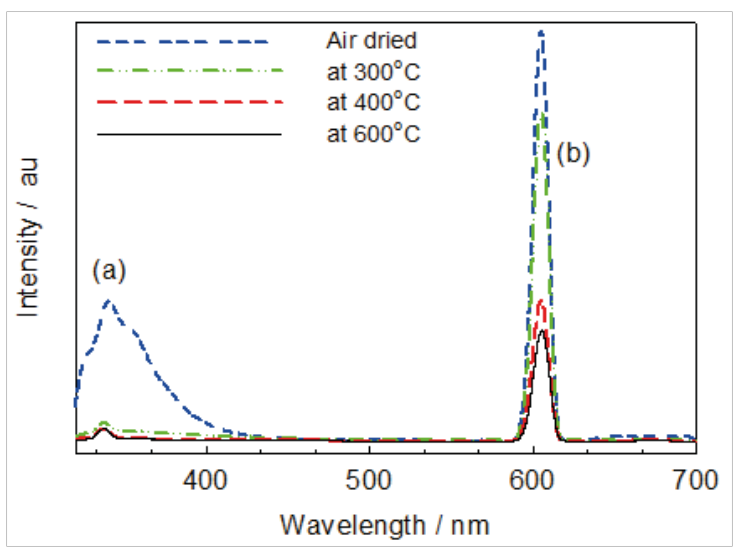

Fig. 4. Photoluminescence spectra of the precursor and ZnO NPs calcined at different temperatures.

A strong and wide PL signal in the range from 590 to $620 \mathrm{~nm}$, with maximum at ca. $605 \mathrm{~nm}$ in the yellow-orange range is attributed to oxygen vacancy (Singh et al., 2008; Aguilar et al., 2009). The low temperature-dried sample provides sufficient ionization energy and increases the concentration of charged zinc interstitials, strengthening the blue emissions. The high temperature calcination induces the outward diffusion of zinc interstitials and diminishes the blue emissions. Therefore, the $\mathrm{ZnO}$ NPs calcined at higher temperatures do not show the presence of zinc interstitial defect states. In general, the smaller the particle size, the larger is the surface oxygen valence content, the higher is the probability of exciton occurrence, and the stronger is the PL signal (Singh et al., 2008; Aguilar et al., 2009). Furthermore, the PL intensity of $\mathrm{ZnO}$ NPs decreases with increasing particle size on increasing calcination temperature to indicate that oxygen vacancy decreases with increasing calcination temperature due to the formation of larger $\mathrm{ZnO}$ crystallite at high temperatures. However, the PL peak positions do not change, indicating that there are a few fixed exciton energy levels on the surface of $\mathrm{ZnO}$ NPs, which are possibly related to the surface states resulting from the oxygen vacancies and adsorbed oxygen. The results show that the smaller the particle size, the more is the surface oxygen content, and the stronger is the PL signal of ZnO NPs. This is due to the fact that the PL signals result mainly from the oxygen vacancies, which favor the photocatalytic reactions, indicating that the surface oxygen vacancies play an important role in exhibiting the material functional performance.

\section{X-Ray diffraction (XRD) of ZnO NPs}

Fig. 5 shows the X-ray diffraction pattern of $\mathrm{ZnO}$ calcined at $700{ }^{\circ} \mathrm{C}$. The experimental $d$-values are in close agreement to the JCPDS $d$-values.

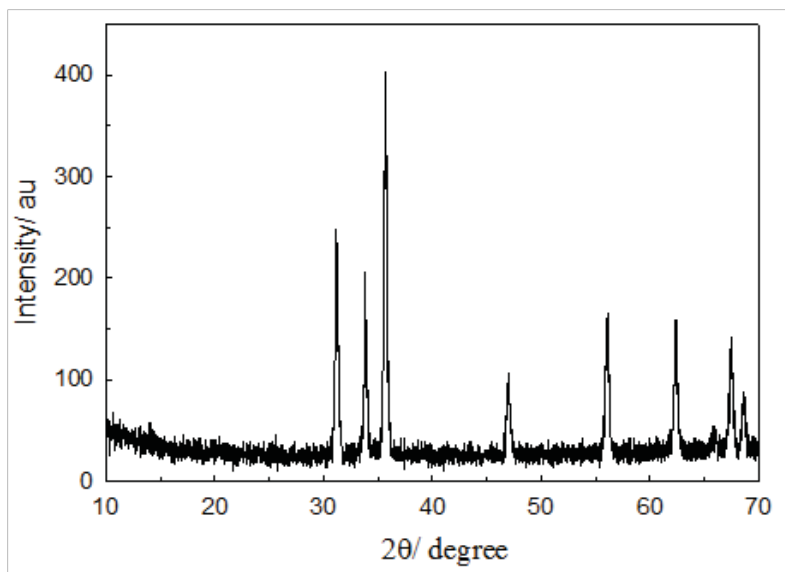

Fig. 5. X-Ray diffraction (XRD) patterns of ZnO NPs prepared from $\mathrm{ZnO}$ precursor by calcination at $700{ }^{\circ} \mathrm{C}$.

It suggests that complete crystallinity of $\mathrm{ZnO} \mathrm{NPs}$ can be achieved on calcining the precursor at $700{ }^{\circ} \mathrm{C}$, which supports the TGA results (vide supra). The characteristic XRD peaks with the corresponding intensities detected at $2 \theta$ positions are summarized in Table 2. In this case, the experimental $d$-values are in good agreement with the JCPDS $d$-values (Jakuphanoglu et al., 2007; Lupan et al., 2008) and $100 \%$ intensity was observed for (101) plane (hkl) similar to pure $\mathrm{ZnO}$. Complete crystallinity could be achieved after calcining the sample at $700^{\circ} \mathrm{C}$. For the XRD diffractogram of $\mathrm{ZnO}$ NPs calcined at $700^{\circ} \mathrm{C}$, the crystallite size $D$, was determined using Debye Scherer formula (Geeetha and Thilagavathi, 2010): 


$$
D=\frac{K \lambda}{\beta \cos \theta}
$$

where $K=0.9$, is the shape factor, $\lambda=1.5408 \AA \AA$, $\theta$ is the diffraction peak angle (Bragg angle) in degrees, and $\beta$ denotes the full width at half maximum (FWHM) in degree, of the corresponding diffraction peak. The crystallite size for (100) plane was found to be $51.59 \mathrm{~nm}$ (eq. 1). The lattice parameters for hexagonal $\mathrm{ZnO}$ calcined at $700{ }^{\circ} \mathrm{C}$ were calculated using equation (2).

$$
\frac{1}{\mathrm{~d}^{2}}=\frac{4}{3}\left(\frac{h^{2}+h k+k^{2}}{a^{2}}\right)+\frac{l^{2}}{c^{2}}
$$

Lattice parameters of $\mathrm{ZnO}$ calcined at $700{ }^{\circ} \mathrm{C}$ were determined from eq. 2 as $a=3.27 \AA$ and $c=5.26 \AA$ which are similar to those of JCPDS standard data $(a=3.25 \AA$ and $c=$ $5.21 \AA$ ) for pure $\mathrm{ZnO}$. It can be inferred from data presented in Table II. that $\mathrm{ZnO}$ NPs prepared by hybridelectrochemical method possess hexagonal wurtzite phase.

\section{Scanning electron microscopy (SEM)}

The SEM images of $\mathrm{ZnO}$ NPs obtained at different calcination temperatures are shown in Fig. 6. The shapes of $\mathrm{ZnO}$ NPs calcined at $700{ }^{\circ} \mathrm{C}$ are granular and almost uniform in size. The mean size of NPs was below $100 \mathrm{~nm}$. This agrees well with the particle size determined by XRD analysis, where the NPs prepared at $700{ }^{\circ} \mathrm{C}$ of calcination temperature give average crystallite size of $53 \mathrm{~nm}$.
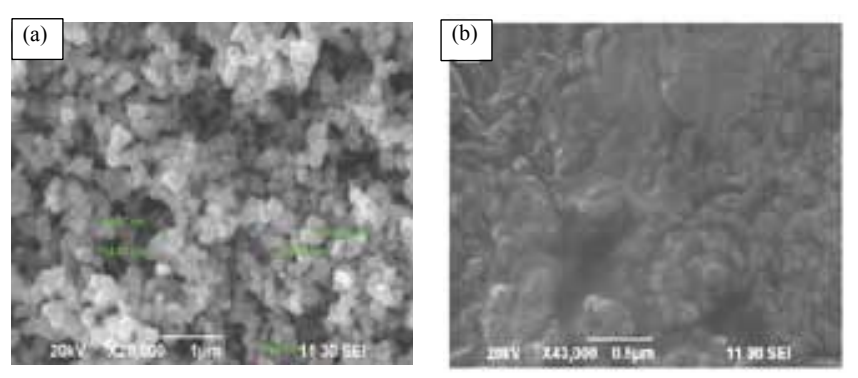

Fig. 6. SEM image of $\mathrm{ZnO}$ NPs calcined at (a) $700{ }^{\circ} \mathrm{C}$ and (b) $300{ }^{\circ} \mathrm{C}$.

Table II. Characteristic $d$ - spacing and $2 \theta$ values observed for pure $\mathrm{ZnO}$ and $\mathrm{ZnO}$ NPs calcined at $700{ }^{\circ} \mathrm{C}$.

\begin{tabular}{cccc|cccc}
\hline & \multicolumn{2}{c}{${\text { Pure } \mathrm{ZnO}^{*}}^{*}$} & \multicolumn{5}{c}{ Calcined ZnO NPs at $700{ }^{\circ} \mathrm{C}$} \\
\hline $\begin{array}{c}d- \\
\text { spacing }\end{array}$ & $2 \theta$ & Intensity & $\mathrm{h} \mathrm{k} 1$ & $\begin{array}{c}d- \\
\text { spacing }\end{array}$ & $2 \theta$ & Intensity & $\mathrm{h} \mathrm{k} 1$ \\
\hline 2.82 & 31.75 & 57.65 & 100 & 2.86 & 31.24 & 64.44 & 100 \\
2.61 & 34.40 & 43.66 & 002 & 2.64 & 33.95 & 48.55 & 002 \\
2.48 & 36.22 & 100.00 & 101 & 2.51 & 35.74 & 100.00 & 101 \\
1.91 & 46.51 & 23.28 & 102 & 1.93 & 47.02 & 18.45 & 102 \\
1.63 & 56.57 & 31.82 & 110 & 1.64 & 56.11 & 34.89 & 110 \\
1.48 & 62.83 & 30.21 & 103 & 1.49 & 62.47 & 25.58 & 103 \\
1.38 & 67.92 & 25.53 & 112 & 1.39 & 67.53 & 22.17 & 112 \\
1.36 & 69.06 & 12.97 & 201 & 1.37 & 68.64 & 12.87 & 201 \\
\hline
\end{tabular}


To monitor the influence of calcination temperature on the formation of $\mathrm{ZnO}$ NPs, SEM image of $\mathrm{ZnO}$ NPs calcined at $300{ }^{\circ} \mathrm{C}$ was also taken. At lower calcination temperatures, the randomly oriented spindle-like $\mathrm{ZnO}$ NPs were observed (Fig. 6(b)). This indicates that calcination temparature plays
This indicates that calcined $\mathrm{ZnO}$ NPs is $100 \%$ pure. Composition of elements in $\mathrm{ZnO}$ NPs prepared by electrochemical method was such that $\mathrm{O}$ was $18.50 \%$ and Zn was $81.50 \%$, which are closer to the calculated values.

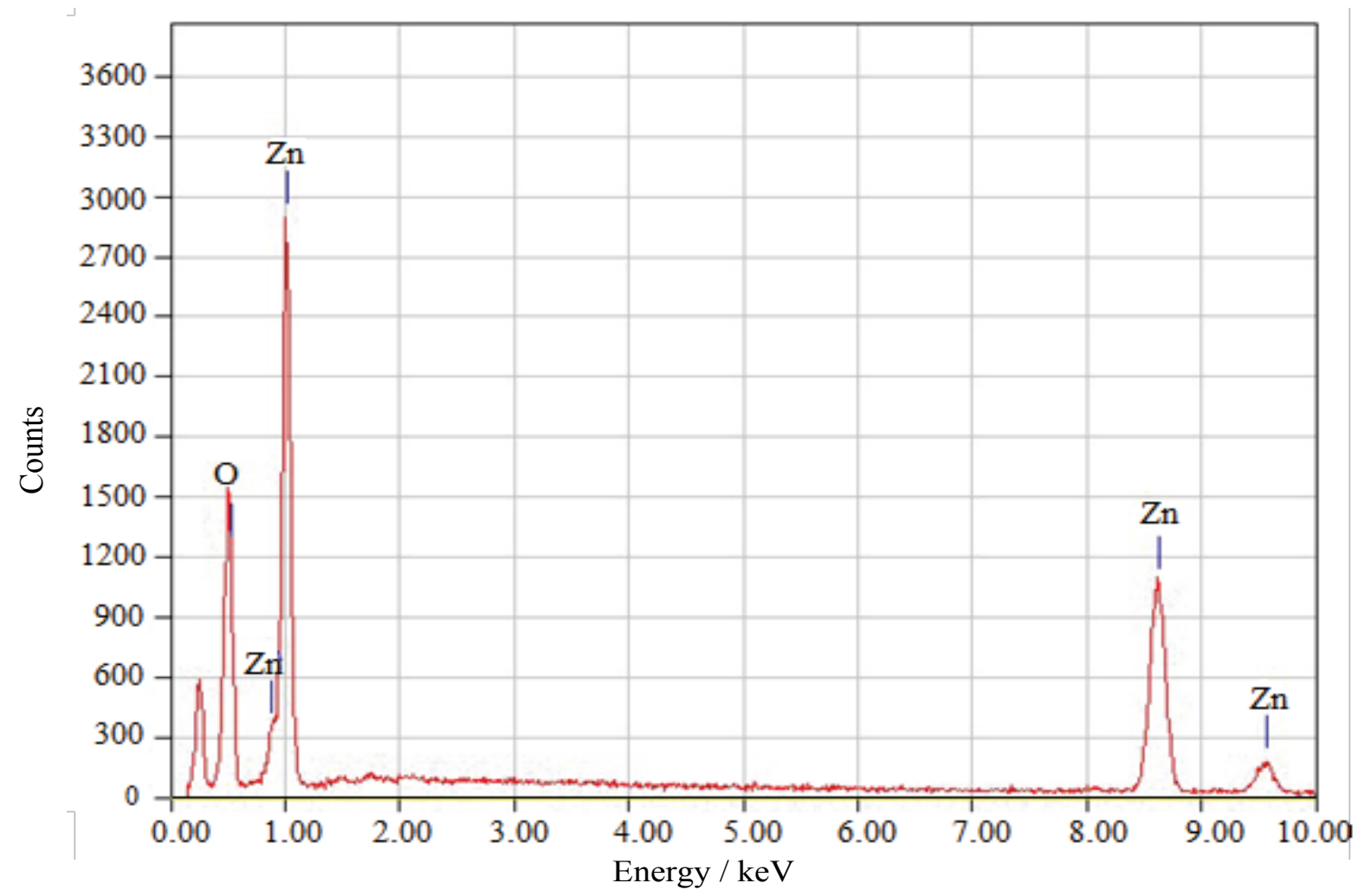

Fig. 7. EDX analysis of ZnO NPs calcined at $700{ }^{\circ} \mathrm{C}$.

a crucial role in the morphology of NPs. This also agrees with the TGA analysis that nucleation of crystalline $\mathrm{ZnO}$ begins at about $300{ }^{\circ} \mathrm{C}$. This is also in agreement with UV-vis results which show that the higher calcination temperature is a requisite for nucleation of $\mathrm{ZnO}$ nanocrystals (Chandrappa et al., 2010).

\section{Energy-dispersive X-ray (EDX) spectroscopy}

The stoichiometry of $\mathrm{ZnO}$ NPs calcined at $700{ }^{\circ} \mathrm{C}$ was examined by the EDX spectrum as shown in Fig. 7. Only signals corresponding to zinc and oxygen have been detected, suggesting that the NPs are indeed made up of $\mathrm{Zn}$ and $\mathrm{O}$ and no other impurities were present in the samples.

\section{Conclusion}

ZnO NPs with sizes less than $100 \mathrm{~nm}$ were successfully prepared from metallic zinc and $\mathrm{NaHCO}_{3}$ by an electrochemical-thermal method. Analyses of $\mathrm{ZnO}$ NPs so prepared have almost uniform morphology when calciniation temperature is near $700{ }^{\circ} \mathrm{C}$ or above. Morphology and sizes of $\mathrm{ZnO}$ could therefore be controlled by changing calcination temperature. The ambient temperature operation of the electrochemical method together with the ease of separation due to the insolubility of precursor in eletrolytic solution have made the hybrid method so attractive. The method is simple and may, therefore, be effectively used to synthesize ZnO NPs on a large scale at a lower cost. 


\section{Acknowledgment}

This study was funded under the sub-project, "Development of Novel Functional and Smart Materials for Technological Applications" (CP-231), under Higher Education Quality Enhancement Project (HEQEP) of the University Grants Commission of Bangladesh.

\section{References}

Aguilar CA, Haight R, Mavrokefalos A, Korgel BA and Chen S (2009), Probing electronic properties of molecular engineered zinc oxide nanowires with photoelectron spectroscopy, ACS Nano. 3: 3057-3062.

Ahmed P, Miran MS, Susan MABH and Mollah MYA. (2013), Growth process of zinc oxide nanoparticles in presence of reverse micelles of anionic and cationic surfactants, J. Bangladesh Chem. Soc. 26: 60.

Bauer C, Boschloo G, Mukhtar E and Hagfeldt A (2001), Electron Injection and Recombination in $\mathrm{Ru}(\text { dcbpy })_{2}(\mathrm{NCS})_{2}$ Sensitized Nanostructured $\mathrm{ZnO}$, J. Phys. Chem. B, 105: 5585-5588.

Brus L (1986), Electronic Wavefunction Semiconductor Clusters: Experiment and theory, J. Phys. Chem. 90: 2555-2560.

Chandrappa, KG, Venkatesha TV, Vathsala K and Shivakumara C (2010), A hybrid electrochemicalthermal method for the preparation of large $\mathrm{ZnO}$ nanoparticles, J. Nanopart. Res. 12: 2667-2678.

Chaturvedi S, Dave PN and Shah NK (2012), Application of nano-catalyst in new era, J. Saudi Chem.Soc. 16: 307-325.

Dong LF, Cui ZL and Zhang ZK (1997), Gas sensing properties of nano- $\mathrm{ZnO}$ prepared by arc plasma method, Nanostruct. Mater. 8: 815-823.

Geeetha D and Thilagavathi, T (2010), Hydrothermal synthesis of nano $\mathrm{ZnO}$ structures from CTAB, Digest J. Nanomater. Biostruct. 5: 297.

Govender K, Boyle DS, O'Brien P, Binks D, West D and Coleman D (2002), Room-temperature lasing observed from $\mathrm{ZnO}$ nanocolumns grown by aqueous solution deposition, Adv. Mater. 14: 1221-1224.

Gupta TK (1990), Application of ZnO Varistors, J. Am. Ceram. Soc. 73: 1817-1840.
Hale, PS, Maddox, LM, Shapter, JG, Voelcker, NH, Ford, MJ and Waclawik, ER, (2005), Growth kinetics and modeling of $\mathrm{ZnO}$ nanoparticles, J. Chem. Edu.. 82: 775 .

Henning, DFK, Hartung R and Reijnen PJ, (1990), Grain Size Control in Low-Voltage Varistors, J. Am. Ceram. Soc. 73: 645-648.

Holleman, AF and Wiberg E (2001), Inorganic Chemistry, Academic Press, San Diego. Houyi, M, Bingsheng Y, Shuyun W, Yongli J, Wei P, Shaoxin H, Shenhao C and Fanjun M (2004), Synthesis of silver and gold nanoparticles by a novel electrochemical method, Chem. Phys. Chem. 5: 68-75.

Jakuphanoglu F, Ilican S, Caglar M, Caglar, Y (2007), The determination of the optical band and optical constants of non-crystalline and crystalline $\mathrm{ZnO}$ thin films deposited by spray pyrolysis, J. Optoelec. $A d v$. Mat. 9: 2180.

Lili W, Youshi W, Yuanchang S and Huiying W (2006), Synthesis of $\mathrm{ZnO}$ nanorods and their optical, Rare Met. 25: 68-73.

Lupan O, Chow L, Chai G and Heinrich H (2008), Fabrication and characterization of $\mathrm{Zn}-\mathrm{ZnO}$ core-shell microspheres from nanorods, Chem. Phy. Lett. 465: 249-253.

Rensmo H, Keis K, Lindstrom H, Solbrand A, Hagfeldt A, Lindquist SE, Wang LN and Muhammed M (1997), High light- to-energy conversion efficiencies for solar cells based on nanostructered $\mathrm{ZnO}$ electrodes, J. Phys. Chem. B, 101: 2598-2601.

Satter SS, Hoque M, Rahman MM, Mollah MYA and Susan MABH (2014), An approach towards synthesis and characterization of $\mathrm{ZnO} @ \mathrm{AgCore@shell}$ nanoparticles in water-in-oil microemulsion $R S C$ Adv., 4:20612.

Singh DP, Singh JAI, Mishr PR, Tiwari RS and Srivastava ON (2008), Synthesis, characterization and application of semiconducting oxide $\left(\mathrm{Cu}_{2} \mathrm{O}\right.$ and $\left.\mathrm{ZnO}\right)$ nanostructures. Bull. Mater. Sci., 31: 319-325.

Syeeda S, Miran MS, Mollah MYA and Rahman MM (2008), Effects of solvents on the growth kinetics of Zinc Oxide Nanoparticles, J. Bangladesh Chem. Soc. 21: 129. 
Tennakone K, Kamura GR, Kottegoda IR and Perera VP (1999), An efficient dye-sensitized photoelectrochemical solar cell made from oxides of tin and zinc, Chem. Commun. 15-16.

Thool GS, Singh AK, Singh RS, Gupta A and Susan $\mathrm{MABH}$ (2014), Facile synthesis of flat crystal $\mathrm{ZnO}$ thin films by solution growth method: A micro-structural investigation, J. Saudi Chem. Soc., 18: $712-721$.

Vágvölgyi V, Hales M, Martens W, Kristóf J, Horváth E and Frost RL (2008), Dynamic and controlled rate thermal analysis of hydrozincite and smithsonite, J. Therm. Anal. Calor. 92: 911-916.

Wang XC, Chen XM and Yang BH (2009), Microstructure and optical properties of polycrystalline $\mathrm{ZnO}$ films sputtered under different oxygen flow rates, J. Alloys Compd. 488: 232-337.
Yongning H, Xiaoliang S and Lidun M (1996), Synthesis and characterization of nanocrystalline-sized zinc oxide, Chin J. Appl. Chem. 13(4): 92.

Zhang XT, Liu YC, Zhang LG, Zhang JY, Lu YM, Shen DZ, Xu W, Zhong GZ, Fan XW and Kong XG (2002), Structure and optically pumped lasing from nanocrystalline $\mathrm{ZnO}$ thin films prepared by thermal oxidation of $\mathrm{ZnS}$ thin films, J. Appl. Phys. 92: 3293-3298.

Zhu H, Yang D, Yu G, Zhang H and Yao K (2006), A simple hydrothermal route for synthesizing $\mathrm{SnO}_{2}$ quantam dots, Nanotech. 17: 2386.

Received: 20 October 2014; Revised: 03 March 2015;

Accepted: 24 March 2015. 